\title{
SILÊNCIO, MISÉRIA E BARBÁRIE: O DECLÍNIO DA EXPERIÊNCIA E O FIM DA ARTE DE NARRAR NA PERSPECTIVA BENJAMINIANA
}

Jean Michel de Lima Silva

\begin{abstract}
RESUMO
O objetivo da pesquisa é abordar, primeiramente, o diagnóstico benjaminiano sobre a perda da experiência na modernidade, sobretudo em uma geração que viveu o terror da Primeira Guerra Mundial (1914-1918). Dessa forma, Benjamin aponta para o empobrecimento da "experiência comunicável", onde até mesmo os veteranos de guerra voltavam mudos dos campos de batalha. Posteriormente, analisaremos a miséria e a barbárie advindas do desregramento do desenvolvimento técnico. $\mathrm{E}$ por fim, trabalharemos ainda os primeiros indícios apontados por Benjamin para a decadência da arte de narrar na modernidade, isto é, por um lado o romance e por outro lado a informação.
\end{abstract}

Palavras-chave: Declínio. Experiência. Barbárie. Arte de narrar. Modernidade.

\section{SILENCE, MISERY AND BARBARISM: THE DECLINE OF EXPERIENCE AND THE END OF THE ART OF NARRATING IN THE BENJAMINIAN PERSPECTIVE}

\begin{abstract}
The purpose of this research is to primarily address Benjamin's diagnosis on the loss of experience in modern times, especially in a generation that faced the terror of World War I (1914-1918). Thus, Benjamin points to the depletion of "communicable experience", where even war veterans were mute upon returning from the battlefields. Subsequently, we will analyze the resulting misery and barbarism of the profligacy of technical development. Finally, we will further work on the first signs pointed out by Benjamin to the decay of the art of storytelling in modern times, that is, novel on one hand and information on the other hand.
\end{abstract}

Keywords: Decline. Experience. Barbarism. Art of narrating. Modern times.

\section{Introdução}

Um dos aspectos centrais da filosofia benjaminiana diz respeito a questão do declínio da experiência (Erfahrung) na sociedade capitalista moderna. As experiências que antes eram transmitidas entre as diversas gerações entraram em decadência. Benjamin faz um diagnóstico preciso das próprias condições de vida de uma geração que passa pelo terror da guerra, pelo desenvolvimento desenfreado da 
técnica e pela instauração da barbárie. Segundo o autor, basta olharmos o ritmo de vida acelerado que foi implantado pelo capitalismo moderno e a velocidade do processo produtivo do trabalho industrial, para nos depararmos com a miséria humana e com a perda do patrimônio cultural da tradição. A organização sociopolítica pré-capitalista do trabalho manifesta-se na atividade artesanal, esta que permite o florescimento da narrativa. Na ótica benjaminiana a arte de narrar se faz semelhante a um ofício manual, pelo seu carácter orgânico e de ritmo lento pautado na tradição comunicativa. Contudo, com a ascensão da burguesia e de suas práticas capitalistas, tais como: o individualismo, a competição desenfreada, o acúmulo do capital, o fetiche do "atual", etc., proporcionam a perda tanto da tradição como também da memória. Os indivíduos já não compartilham mais suas experiências, pois o processo de fragmentação é tão grande que eles próprios não se reconhecem na tradição. É inegável uma espécie de "abismo" estabelecido entre uma geração e outra que priva-os de intercambiar as experiências.

A presente pesquisa pretende abordar o declínio da experiência exposta por Benjamin na modernidade, onde as pessoas mais velhas não podem mais recorrer nem aos provérbios nem as histórias para repassar suas experiências a juventude. Ulteriormente explicitaremos também os reflexos diretos do declínio da experiência sobre a narrativa. Será que a arte de narrar chegou ao seu fim?

\section{A perda da experiência e o silêncio do terror}

Antes de nos determos propriamente sobre a questão do declínio da experiência (Erfahrung) na modernidade, devemos esclarecer a concepção benjaminiana de experiência, exposta no texto "Experiência e Pobreza" (Erfahrung und Armut) de 1933, onde se verifica ser a experiência um conhecimento transmitido entre gerações, a saber, um conhecimento acumulativo e de caráter coletivo que se estabelece lentamente através da transmissão das sucessivas gerações. Vale ressaltar ainda a utilização ilustrativa de Benjamin da própria literatura para esclarecer sua concepção de experiência, narrando assim, a fábula de um velho que no leito de morte demonstra aos seus filhos a existência de um tesouro enterrado em seu vinhedo. Os filhos ouvindo a revelação feita pelo pai começam a cavar por todos os lados a terra, mas não encontram nem vestígio do suposto tesouro. 
Posteriormente com a chegada do outono, os jovens percebem que as vinhas tiveram um aumento significativo em sua produção e que nenhuma outra se compara a elas em toda a região. É então que compreendem o verdadeiro tesouro que o pai lhes havia deixado, isto é, a experiência de que "a benção não se esconde no ouro, mas no trabalho"1.

A partir desse entendimento, podemos nos questionar por quais meios as experiências são transmitidas? Ou ainda de que forma a maturidade comunica suas experiências às novas gerações? A postura de Walter Benjamin sobre essa transmissão é claramente evidenciada nesta passagem de "Experiência e Pobreza":

\begin{abstract}
Sabia-se muito bem o que era experiência: as pessoas mais velhas sempre a passavam aos mais jovens. De forma concisa, com a autoridade da idade, em provérbios; ou de forma prolixa com sua loquacidade, em histórias; ou ainda através de narrativas de países estrangeiros, junto à lareira, diante de filhos e netos. ${ }^{2}$
\end{abstract}

Descobre-se assim, que as experiências de gerações mais antigas são propagadas as mais jovens por intermédio das fábulas, das histórias, das parábolas e dos provérbios. Nesse sentido, a experiência se mostra como um conhecimento prático "incorporado" pelos indivíduos, quer dizer, um conhecimento baseado na construção da tradição e principalmente na memória. Contudo, Benjamin observa na modernidade um declínio ${ }^{3}$ acentuado da própria experiência, o homem moderno encontra-se impossibilitado de invocar o saber da tradição, restando-lhe somente silenciar diante da realidade.

Posta assim a questão da perda da experiência, Benjamin problematiza: "A quem ajuda, hoje em dia, um provérbio? Quem sequer tentará lidar com a juventude invocando sua experiência?"4. Ora, em uma geração que presencia o terror exposto pela Primeira Guerra Mundial não é estranho que as pessoas se tornem mais pobres em "experiência comunicável". Os indivíduos silenciam diante das experiências desmoralizantes propiciadas pela Primeira Guerra Mundial, onde a título de exemplo

1 BENJAMIN, Walter. Experiência e Pobreza. In: Documentos de cultura, documentos de barbárie: escritos escolhidos. Tradução Celeste $\overline{\mathrm{H}}$. M. Ribeiro de Sousa [et al.]. São Paulo: Cultrix, 1986. p.195.

2 Ibid., p.195.

3 É o que diz Walter Benjamin, a respeito do evidente declínio da experiência: "Uma coisa está clara: a cotação da experiência baixou, e precisamente numa geração que de 1914 a 1918 viveu uma das experiências mais monstruosas da História Universal." (Ibid., p.195).

4 Ibid., p.195. 
podemos citar: as estratégias militares das trincheiras, o desenvolvimento bélico alcançado (arame farpado, tanques, metralhadoras e lança-chamas), a fome, a miséria, a proliferações de doenças e o advento da inflação no cenário econômico mundial. Segundo Benjamin, o "frágil e minúsculo corpo humano" ${ }^{5}$ encontrava-se desabrigado em meio as explosões, bombardeios e correntes destruidoras. Percebese uma "cortina de névoa" que povoa as mentes dessa geração, inclusive dos próprios veteranos ${ }^{6}$ de guerra que nada conseguem comunicar de suas experiências nos campos de batalhas. Como alerta Benjamin:

Talvez isso não seja tão estranho como parece. Já não se podia constatar, naquela época, que as pessoas voltavam mudas do campo de batalha? Não voltavam enriquecidas, senão mais pobres em experiência comunicável. Os livros sobre a guerra que proliferavam nos dez anos seguintes não continham experiências transmissíveis de boca em boca. ${ }^{7}$

Convém ressaltar que não só a guerra, mas também, o desenvolvimento desenfreado da técnica que propicia a guerra imperialista proporciona a miséria humana. Nesse sentido, Benjamin aponta que a medida em que a "sabedoria antiga" torna-se apenas um puro conhecimento científico implanta-se na verdade a "tragédia moderna". Cumpre-nos examinarmos, neste passo a nova forma de miséria que se abate sobre a humanidade com o desenvolvimento tecnológico.

\section{0 desenvolvimento técnico na modernidade: miséria, barbárie e cultura de vidro}

Uma geração que há bem pouco tempo se locomovia através de bondes puxados a cavalos, tem seu horizonte existencial completamente transformado com

\footnotetext{
5 Ibid., p.195.

${ }^{6} \mathrm{O}$ historiador britânico Martin Gilbert em sua obra "A Primeira Guerra Mundial", expõe a experiência aterrorizante e silenciadora do seu tio nos campos de batalha: "Um dos meus primeiros professores de História, A. P. White, tinha também combatido nas trincheiras: costumava andar para lá e para cá na sala de aula, com uma escova ao ombro, enquanto entoava canções militares. Quando comecei a trabalhar neste livro, foram publicadas as suas cartas enviadas das trincheiras, que revelavam grande sofrimento e sensibilidade. O irmão mais velho do meu pai, o meu tio Irving, tinha lutado no Somme: a sua experiência tinha-o aterrorizado, e nós, os rapazes da família, tínhamos sido advertidos para não the fazermos perguntas sobre esse assunto." (GILBERT, Martin. A Primeira Guerra Mundial. Tradução de Francisco Paiva Boléo. Lisboa-Portugal: A Esfera dos Livros, 2007. p.14).

7 BENJAMIN, op. cit., p.195.
} 
o incremento da técnica ${ }^{8}$. Nesta perspectiva pode-se dizer que "uma miséria totalmente nova se abateu sobre o homem com esse desenvolvimento monstruoso da técnica"9. Não quer dizer isso, entretanto, que a "riqueza das ideias" não se difundiu entre as pessoas. Mas sim, que esse processo de "reavivamento" da astrologia, da ioga, da quiromancia, da gnose, da escolástica, etc., não é um "reavivar" legítimo. "Aliás, não é um reavivar autêntico que acontece, mas uma galvanização"10. Como se vê, Benjamin percebe que essa suposta "riqueza de ideias" e o "reavivar" são processos de revestimento superficial na modernidade, peculiares ao status quo da civilização: seu distanciamento das coisas concretas da natureza, que foram substituídas pela fantasmagoria, tal como Benjamin a aponta, exposta nos quadros de James Ensor ${ }^{11}$ :

Somos levados a pensar nos magníficos quadros de Ensor, nos quais uma fantasmagoria povoa as ruas das grandes cidades: pequenos-burgueses com fantasias carnavalescas, máscaras disformes brancas de farinha, coroas de purpurina nas cabeças, dançam a perder de vista ao longo das ruelas. Esses quadros são talvez nada além de cópia da Renascença caótica e horripilante, na qual tantos depositam suas esperanças. ${ }^{12}$

A discussão aqui gravita em torno de nossa pobreza de experiência, que ganha contornos nítidos de um "rosto"13 na modernidade. Visto que, as diversas cosmovisões apenas nos mostraram a simulação e imitação da experiência. Nesta perspectiva o que nos resta é confessar nossa pobreza, e mais ainda, admitir que

8 Em relação ao desenvolvimento da técnica na modernidade, Benjamin se utiliza dos romances de Paul Scheerbart para problematizar a transformação dos homens tradicionais, quer dizer, "Scheerbart se interessa pela questão, de que modo nossos telescópios, nossos aviões e foguetes transformam os homens tradicionais em criaturas novas, dignas de atenção e respeito. Aliás, essas criaturas já falam uma língua totalmente nova. E o decisivo nela é a tendência construtiva e arbitrária, contrastando com a dimensão orgânica". (Ibid., p.197).

9 lbid., p.195.

${ }^{10}$ Ibid., p.196.

${ }^{11}$ James Sidney Edouard Baron Ensor (1860-1949) foi um pintor, gravador e desenhista belga. Suas obras exerceram grande influência tanto sobre o expressionismo, como também, sobre o surrealismo. É bem verdade que seus quadros cotiam uma crítica social de plano de fundo, onde retratavam pessoas mascaradas, pequenos-burgueses e a fantasmagoria das cidades, a título de exemplo temos: Entrada de Cristo em Bruxelas, $O$ esqueleto pintor, A morte e as máscaras, etc. Para maiores detalhes, conferir a obra: TRICOT, Xavier et al. Catálogo razonado de la obra gráfica James Ensor de lo real a lo imaginario colección del banco KBC, Bélgica. México: Museo Nacional de Arte, 2008.

12 BENJAMIN, op. cit., p.196.

${ }^{13}$ Benjamin faz referência ao rosto da pobreza na seguinte passagem de Experiência e Pobreza: "Aqui se evidencia claramente: nossa pobreza de experiência nada mais é que uma parte da grande pobreza que ganhou novamente um rosto - tão nítido e exato como o do mendigo medieval." (Ibid., p.196). 
ela não se faz presente apenas particularmente, mas que perpassa a esfera de toda a humanidade. Como se pode notar, Benjamin busca apresentar uma nova forma de barbárie, isto é, um conceito positivo e novo de barbárie.

\begin{abstract}
Barbárie? Pois é. Nós a mencionamos para introduzir um conceito novo, um conceito positivo de barbárie. Pois o que traz ao bárbaro a pobreza de experiência? Ela o leva a começar do começo; a começar de novo; a saber se virar com pouco; a saber construir com pouco, sem olhar nem para a direita nem para a esquerda. ${ }^{14}$
\end{abstract}

Ora, se nos encontramos em um estado onde foram "subtraídos" a experiência, a memória e principalmente o patrimônio cultural da humanidade, vivenciamos uma época onde uma nova espécie de barbárie se instaura. No que diz respeito a peculiaridade deste novo conceito de barbárie, Benjamin aponta para o seu aspecto positivo. Este permite o "começar do começo", quer dizer, o puro recomeço, que exige do homem uma nova postura: o despojamento. À guisa de exemplo desse recomeço, podemos citar os grandes construtores da humanidade: Descartes alicerça o seu edifício filosófico na certeza do "Penso, logo existo"; Einstein direciona seu interesse para as equações de Newton e astronomia, e ainda os artistas que se fundamentavam na matemática para construir o mundo (sejam os cubistas com as formas estereométricas, sejam as figuras de Klee baseadas na engenharia).

O discernimento essencial, que deve ser alcançado em uma época que apaga suas pegadas ${ }^{15}$ e não quer deixar rastros de sua existência, consiste no aparecimento de uma "cultura de vidro". Benjamin retoma Paul Scheerbart e suas casas de vidro, para explicitar uma desilusão e miséria advindas da cultura capitalista burguesa, isto é, de uma geração onde nada se fixa e que necessariamente nutre sempre o "novo" e o "atual". "Será que pessoas como Scheerbart sonham com construções de vidro porque professam uma nova pobreza?"16 Convém notar que uma das características fundamentais que compõe o vidro é justamente sua forma "lisa e dura". Sem esquecer de seu aspecto "frio e

\footnotetext{
${ }_{15}^{14}$ Ibid., p.196.

${ }^{15}$ Benjamin discute sobre o "apagar das pegadas" em sua obra Experiência e Pobreza onde faz relação direta ao poema de Bertold Brecht: "Um belo verso de Brecht nos ajuda a sair daqui, para longe daqui: 'Apague as pegadas!' - diz o refrão do poema inicial do Manual para habitantes das cidades." (Ibid., p. 197). Ver também: BRECHT, Bertold. Poemas 1913-1956. Tradução de Paulo César de Souza. São Paulo: Editora 34, 2000.

${ }^{16}$ BENJAMIN, op. cit., p.197.
} 
sóbrio" e de seu design inovador. Podemos perceber ainda que o vidro não possui "aura" alguma e que é inimigo por um lado do mistério, e inimigo por outro lado da própria propriedade. Não seria o vidro uma metáfora para a perda de memória, para o fenômeno, na Modernidade, da indiferença de um diante do outro? Uma vez que ele não deixa marcas. $O$ vidro permite que o olhar o trespasse, sem que esse olhar deixe nenhum vestígio de calor humano. A arquitetura moderna ressalta as construções de vidro e aço que não proporcionam vestígios, nem marcas e muito menos rastros. Benjamin explica:

Foi o que fizeram Scheerbart com seu vidro e a Bauhaus com seu aço: eles criaram espaços nos quais é difícil deixar rastros. 'Pelo que foi dito', explicou Scheerbart há vinte anos, 'podemos falar de uma cultura de vidro. O novo ambiente de vidro transformará por completo o homem. ${ }^{\text {,17 }}$

Por tudo o que foi visto até aqui percebemos que na modernidade há um claro declínio da experiência e consequentemente um acentuado empobrecimento do patrimônio da humanidade, constantemente permutado pela moeda do "novo" e do "atual". A pobreza de experiência não significa que o homem moderno seja ignorante, muito pelo contrário, eles são na verdade "devoradores" de cultura, e por isso seguem supersaturados. Os homens não desejam uma "nova experiência", mas sim, procuram assumir a barbárie instaurada. Benjamin almeja que disso resulte algo decente. Tenha-se presente que "em suas construções, seus quadros, suas narrativas, a humanidade se prepara para sobreviver, se for preciso, à cultura"18, essa sobrevivência esta pautada principalmente no humor, isto é, "ela o faz rindo". Após todas estas noções, resta-nos ainda demonstrar os reflexos desta perda de experiência na modernidade em relação à arte de narrar. Será que a arte de narrar encontra-se em vias de extinção?

4 Os reflexos do declínio da experiência sobre a arte de narrar na modernidade: decadência, romance e informação

\footnotetext{
${ }^{17}$ lbid., p. 197.

18 lbid., p. 198. 
Benjamin na obra: O narrador. Considerações sobre a obra de Nikolai Leskov $^{19}$, expõe que a figura do narrador ${ }^{20}$, que aliás tanta familiaridade nos traz, não se encontra mais presente na modernidade. Mostrando-se na verdade, cada dia mais distante ${ }^{21}$ e afastada de nossa realidade cotidiana. A simples narração de uma experiência já nos gera "desconforto e obstáculo", retratando um cenário de pura extinção da própria arte de narrar:

É a experiência de que a arte de narrar está em vias de extinção. São cada vez mais raras as pessoas que sabem narrar devidamente. Quando se pede num grupo que alguém narre alguma coisa, o embaraço se generaliza. É como se estivéssemos privados de uma faculdade que nos parecia segura e inalienável: a faculdade de intercambiar experiências. ${ }^{22}$

A causa da manifestação desse fenômeno na modernidade se dá pela acentuada decadência da experiência. É inegável que a experiência vem perdendo seu imenso valor e que seus níveis apresentam índices baixíssimos a cada dia. Segundo Benjamin, basta somente abrirmos um jornal para constatarmos a perda do patrimônio humano, a guerra, a barbárie e as transformações do mundo ético. Nesse sentido o homem moderno se depara com a ausência da experiência transmitida de

\footnotetext{
${ }^{19}$ No que diz respeito a importância do escritor russo Nikolai Leskov (1831-1895) temos as considerações de Benjamin sobre suas narrativas: "A significação de Leskov está em suas narrativas, que pertencem a uma fase posterior. Desde o fim da guerra houve várias tentativas de difundir essas narrativas nos países de língua alemã." (BENJAMIN, Walter. O narrador. Considerações sobre a obra de Nikolai Leskov. In:_ Magia e técnica, arte e política: ensaios sobre literatura e história da cultura. Tradução Sérgio Paulo Rouanet. São Paulo: Brasiliense, 1994. p.197).

${ }^{20}$ A sensibilidade de Benjamin constata a formação de dois grupos de narradores ao longo da história, isto é, por um lado "o camponês sedentário" e por outro lado o "marinheiro comerciante". O primeiro grupo ressalta o narrador interno que nunca saiu de seu país, mas que domina suas "histórias e tradições", entre os autores alemães modernos se destacam Hebel e Gotthelf. Já o segundo grupo, apresenta o narrador como alguém vindo de terras longínquas e que "tem muito o que contar" em decorrência de suas experiências nas viagens, entre eles podemos citar Sielsfield e Gerstäcker. Percebe-se que o reino narrativo em sua extensão histórica, só poderá ser verdadeiramente compreendido pela interpenetração desses dois tipos. Vale ressaltar que o sistema corporativo medieval tem uma importância fundamental nesta interpenetração. Conforme expõe Benjamin: "Se os camponeses e os marujos foram os primeiros mestres da arte de narrar, foram os artífices que a aperfeiçoaram. No sistema corporativo associava-se o saber das terras distantes, trazidos para casa pelos migrantes, com o saber do passado, recolhido pelo trabalhador sedentário." (Ibid., p.199).

${ }^{21} \mathrm{Em}$ relação ao distanciamento do narrador, temos que: "Por mais familiar que seja seu nome, o narrador não está de fato presente entre nós, em sua atualidade viva. Ele é algo de distante, e que se distancia ainda mais." (Ibid., p.197).

${ }^{22}$ Ibid., p.197-198.
} 
"boca em boca", que outrora era a fonte da arte de narrar, quer dizer, "a experiência que passa de pessoa a pessoa é a fonte a que recorreram todos os narradores" ${ }^{23}$.

Registra-se, ainda que uma das características mais significativas dos narradores natos é justamente a presença do senso prático, que caracteriza a "natureza da verdadeira narrativa" e seu aspecto utilitário. O narrador sempre transmite algo, seja comunicando um ensinamento moral, seja dando uma sugestão prática, ou até mesmo uma norma de vida. "De qualquer maneira, o narrador é um homem que sabe dar conselhos" ${ }^{24}$. Mas qual é o real motivo para que essa capacidade de "aconselhar" seja hoje considerada ultrapassada e antiquada? Ora, em uma sociedade onde as experiências já não são mais transmissíveis e até mesmo onde nossa inalienável faculdade de intercambiar experiências acaba se perdendo, não é difícil compreender porque não conseguimos mais aconselhar ninguém, nem a nós mesmos. Vivemos no podium da ciência que precisa analisar todos os fatos de forma laboratorial. A experiência não tem permissão para entrar nesse contexto. Ela é tecida no inconsciente. Partindo dessa ideia, Benjamin percebe que "o conselho tecido na substância viva da existência tem um nome: sabedoria. A arte de narrar está definhando porque a sabedoria - o lado épico da verdade - está em extinção." 25 É bem verdade que todo esse processo de decadência que se abateu sobre a arte de narrar vem de longas datas, e que "tem se desenvolvido concomitantemente com toda uma evolução secular das forças produtivas" ${ }^{26}$.

Benjamin faz menção ainda ao surgimento do romance moderno como o primeiro indício do enfraquecimento da narrativa. Como se há de verificar, o romance se distingue da arte de narrar, pois possui um vínculo essencial com o livro. Assim, sua disseminação só é possível com o advento da imprensa. A natureza fundamental que caracteriza o romance, isto é, "que ele nem procede da tradição oral nem a alimenta" 27 , o diferencia de outras formas de prosa, tais como: os contos, as lendas e as novelas. Enquanto o narrador extrai da experiência o que conta, seja utilizando-se de sua própria experiência ou mesmo experiências referidas por outros,

\footnotetext{
${ }^{23}$ Ibid., p.198.

${ }^{24}$ Ibid., p.200.

${ }^{25}$ Ibid., p.200-201.

${ }^{26}$ Ibid., p.201.

${ }^{27}$ Ibid., p.201.
} 
ele incorpora em seus ouvintes as experiências narradas. Neste procedimento narrativo podemos observar o intercambiar de experiências entre aquele que narra e aquele que ouve, daí resultando uma coletividade. O romance por sua vez, traz em seu bojo o indivíduo isolado, segregado, que não aconselha ninguém e nem muito menos recebe conselhos. Benjamin ilustra todo esse cenário romântico com a figura de Dom Quixote ${ }^{28}$ que resiste aos conselhos e que não possui a menor fagulha de sabedoria.

Cumpre examinarmos, neste passo outro fator mais ameaçador que o próprio romance para o declínio da narrativa, a saber, uma nova ${ }^{29}$ forma de comunicação humana apontada por Benjamin na modernidade. Tenha-se presente que a consolidação da burguesia e a invenção da imprensa como instrumento do alto capitalismo, foram fatores decisivos que propiciaram a ascensão desta nova forma de comunicação, isto é, a informação, que passa a influenciar categoricamente a forma épica. Para explicar a essência da informação, Benjamin se utiliza da famosa fórmula do jornalista francês Hippolyte de Villemessant (1810-1879):

Villemessant, o fundador do Figaro, caracterizou a essência da informação com uma fórmula famosa. 'Para meus leitores', costumava dizer, 'o incêndio num sótão do Quartier Latin é mais importante que uma revolução em Madri'. Essa fórmula lapidar mostra claramente que o saber que vem de longe encontra hoje menos ouvintes que a informação sobre acontecimentos próximos. ${ }^{30}$

Cotidianamente chegam até nós informações do mundo todo, através de jornais, diários, revistas, etc., contudo continuamos pobres em histórias surpreendentes e relatos miraculosos. Em decorrência da comunicação informativa que faz uma verificação imediata e puramente explicativa ${ }^{31}$ dos fatos. A informação

${ }^{28}$ A discussão gravita em torno da seguinte passagem: "O primeiro grande livro do gênero, Dom Quixote, mostra como a grandeza de alma, a coragem e a generosidade de um dos mais nobres heróis da literatura são totalmente refratárias ao conselho e não contêm a menor centelha de sabedoria." (Ibid., p.201). Ver também o romance: CERVANTES, Miguel de. Dom Quixote. Adaptação de Michael Harrison. São Paulo: Editora Ática, 2003.

29 Interessante se faz notar esse aspecto ameaçador da informação exposto por Benjamin na obra $O$ narrador. Considerações sobre a obra de Nikolai Leskov: "Ela é tão estranha à narrativa como o romance, mas é mais ameaçadora e, de resto, provoca uma crise no próprio romance. Essa nova forma de comunicação é a informação." (BENJAMIN, op. cit., p.202).

${ }^{30}$ Ibid., p.202.

${ }^{31}$ Benjamin demonstra que a arte de narrar se esquiva das explicações. E essa é a sua grandeza, a grandeza da obra de Homero e favorecer a interpretação. A narração proporciona ao leitor mais liberdade para interpretar os fatos e ampliar o episódio narrado. Rigorosamente falando, "Metade da arte narrativa está em evitar explicações. Nisso Leskov é magistral. (Pensemos em textos como 
possui um curto espaço de tempo existencial, pois seu valor depende diretamente do caráter de novidade nela contido. Dessa forma, a informação só "vive" e tem alguma relevância no momento em que é nova, devendo explicar-se inteiramente nesse breve período de tempo. Com o surgimento da informação não temos mais a conservação das histórias, a arte de contá-las novamente se esvai pela perda da experiência e da memorização. "Muito diferente é a narrativa. Ela não se entrega. Ela conserva suas forças e depois de muito tempo ainda é capaz de se desenvolver." ${ }^{32}$ Benjamin qualifica ainda o narrador entre os mestres e os sábios, em decorrência de seu dom de dar conselhos para uma diversidade de casos. $O$ narrador tem a capacidade de recorrer não somente a sua própria experiência, mas também as experiências de outrem. Com isso, assimila a "substância mais íntima" da tradição e pode transmiti-la as novas gerações. Sua dignidade consiste em poder contar "toda uma vida".

Em suma, Benjamin aborda as principais características do narrador para demonstrar o fenômeno do distanciamento e da extinção do contador de histórias. Para ele torna-se cada vez mais difícil encontrar pessoas capazes de narrar adequadamente. Esse fenômeno tem como causa a decadência da experiência transmissível entre gerações. Ora, se a fonte onde o narrador busca as experiências humanas entra em decadência, a própria arte de narrar se vê em vias de extinção. Daí resulta, que a narrativa torna-se na modernidade "arcaica" e que o primeiro indício de seu enfraquecimento é o surgimento do romance. Contudo, Benjamin expõe algo mais ameaçador que o próprio romance para a extinção da arte-denarrar: a difusão da comunicação informativa. "Se a arte da narrativa é hoje rara, a difusão da informação é decisivamente responsável por esse declínio"33.

\section{Considerações Finais}

Tendo em vista os aspectos observados, percebe-se claramente um acentuado declínio da experiência (Erfahrung) na modernidade. Segundo Benjamin,

$A$ fraude, ou $A$ águia branca). O extraordinário e o miraculoso são narrados com a maior exatidão, mas o contexto psicológico da ação não é imposto ao leitor. Ele é livre para interpretar a história como quiser, e com isso o episódio narrado atinge uma amplitude que não existe na informação." (Ibid., p.203).

32 Ibid., p.204.

${ }^{33}$ lbid., p.203. 
as experiências que antes eram transmitidas entre gerações se findaram. Dessa forma, o homem moderno encontra-se impossibilitado de recorrer a sabedoria da tradição contida nas fábulas, histórias, parábolas e provérbios. Em uma geração que viveu os horrores da Primeira Guerra Mundial (1914-1918) é evidente o empobrecimento da "experiência comunicável". Inclusive, os próprios veteranos de guerra voltavam dos campos de batalha mudos e sem a menor condição de comunicar suas experiências nos combates.

Como vimos, não só o terror da guerra, mas também o desenvolvimento desenfreado da técnica proporcionaram a miséria humana. Sendo assim, a própria "riqueza de ideias" que se difundiu entre os indivíduos no "reavivar" da astrologia, da ioga, da quiromancia, etc., não é um processo autêntico, mas apenas uma "galvanização". Benjamin vê que essa suposta "riqueza de ideias" é na verdade uma simulação, uma imitação e um revestimento superficial da experiência. Devemos confessar nossa pobreza de experiência a nível de humanidade e não somente como particular. Nesta perspectiva nos deparamos com uma nova espécie de barbárie, uma barbárie positiva, que nos permite "começar do começo", um começar novamente e principalmente "saber construir com pouco". Ora, em uma época que busca "apagar suas pegadas" e não quer deixar rastro algum, percebe-se o aparecimento de uma "cultura de vidro" onde nada se fixa e que a moeda do "atual" é uma constância. O vidro por sua "lisura e dureza" proporcionam uma construção sem vestígios, além de se adequar perfeitamente ao "novo" por seu design moderno e inovador.

Em suma, em decorrência da pobreza de experiência que se abateu na humanidade, a arte de narrar encontra-se em vias de extinção. A figura do narrador é cada vez mais rara e encontra-se mais distante de nossa realidade existencial. Como se pôde notar a arte de "dar conselhos", própria do narrador, descobre-se decadente e antiquada na modernidade. O primeiro indício apontado por Benjamin para o declínio da narrativa é justamente o aparecimento do romance moderno. Mas não só ele, existe algo ainda mais ameaçador para o narrador, a saber, a informação. Esta que possui um curto espaço de tempo existencial, pois sua validade depende da atualidade da notícia informada. Dessa forma, a conservação 
das histórias e a arte de transmiti-las a outras gerações se perde, restando-nos o declínio da experiência e da memória. 


\section{REFERÊNCIAS}

BENJAMIN, Walter. Documentos de cultura, documentos de barbárie: escritos escolhidos. Tradução Celeste H. M. Ribeiro de Sousa [et al.]. São Paulo: Cultrix, 1986.

. Experiência e Pobreza. In: Documentos de cultura, documentos de barbárie: escritos escolhidos. Tradução Celeste H. M. Ribeiro de Sousa [et al.]. São Paulo: Cultrix, 1986. p.195-198.

. Magia e técnica, arte e política: ensaios sobre literatura e história

da cultura. Tradução Sérgio Paulo Rouanet. São Paulo: Brasiliense, 1994.

O narrador. Considerações sobre a obra de Nikolai Leskov. In:

Magia e técnica, arte e política: ensaios sobre literatura e história da cultura. Tradução Sérgio Paulo Rouanet. São Paulo: Brasiliense, 1994. p. 197-221.

BRECHT, Bertold. Poemas 1913-1956. Tradução de Paulo César de Souza. São Paulo: Editora 34, 2000.

CALLADO, Tereza de Castro. Walter Benjamin e a experiência da origem. Fortaleza: EdUECE, 2006.

CERVANTES, Miguel de. Dom Quixote. Adaptação de Michael Harrison. São Paulo: Editora Ática, 2003.

FILHO, José Edmar Lima; CALLADO, Tereza de Castro. Magia e llusão: as duas faces de Janus da técnica na reflexão de Walter Benjamin. Cadernos Walter Benjamin, v. 5, n. 5, p. 01-15, 2010.

GILBERT, Martin. A Primeira Guerra Mundial. Tradução de Francisco Paiva Boléo. Lisboa-Portugal: A Esfera dos Livros, 2007.

TRICOT, Xavier et al. Catálogo razonado de la obra gráfica James Ensor de lo real a lo imaginario colección del banco KBC, Bélgica. México: Museo Nacional de Arte, 2008. 